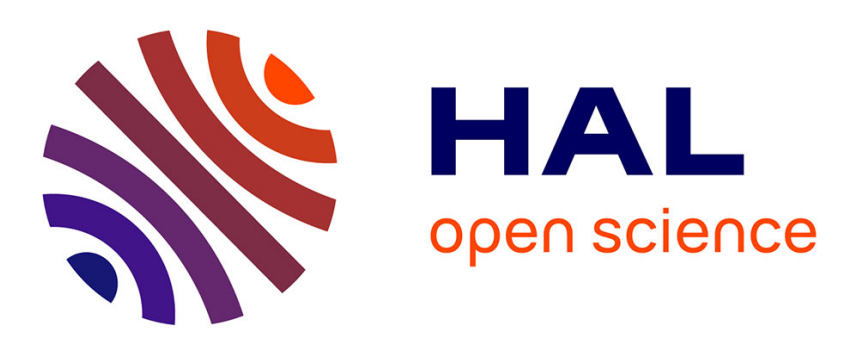

\title{
Evolution of PV solar modules parameters operating in extreme environments
}

\author{
Jean Zaraket, Ninel Kokanyan, Michel Aillerie, Chafic Salame
}

\section{To cite this version:}

Jean Zaraket, Ninel Kokanyan, Michel Aillerie, Chafic Salame. Evolution of PV solar modules parameters operating in extreme environments. Technologies and materials for renewable energy, environment and sustainability: TMREES20, Jun 2020, Athens, Greece. pp.020058, 10.1063/5.0032651 . hal-03092715

\section{HAL Id: hal-03092715 \\ https://hal.univ-lorraine.fr/hal-03092715}

Submitted on 4 May 2021

HAL is a multi-disciplinary open access archive for the deposit and dissemination of scientific research documents, whether they are published or not. The documents may come from teaching and research institutions in France or abroad, or from public or private research centers.
L'archive ouverte pluridisciplinaire HAL, est destinée au dépôt et à la diffusion de documents scientifiques de niveau recherche, publiés ou non, émanant des établissements d'enseignement et de recherche français ou étrangers, des laboratoires publics ou privés. 


\title{
Evolution of PV Solar Modules Parameters Operating in Extreme Environments
}

\author{
Jean Zaraket ${ }^{1,2, a)}$, Ninel Kokanyan ${ }^{3}$, Michel Aillerie ${ }^{2}$, and Chafic Salame ${ }^{1,4}$ \\ ${ }^{I}$ CEER, Faculty of Sciences II, Lebanese University, B.P 90656 Jdeidet El Mten, Lebanon \\ ${ }^{2}$ Université de Lorraine, CentraleSupélec, LMOPS, F-57000 Metz, France \\ ${ }^{3}$ CentraleSupélec, Université de Lorraine, LMOPS, F-57000 Metz, France \\ ${ }^{4}$ CNRSL, National Council for Scientific Research, Beirut, Lebanon \\ Corresponding author: jean.zaraket@hotmail.com
}

\begin{abstract}
In a photovoltaic power plant, cells and panels often work under non-standard conditions due to mismatch between modules or due to non-uniform sun irradiation. These working conditions are at the origin of electrical and thermal stresses creating hot spots that can go as far as the complete degradation of the module. In this contribution, we analyse the influence of the combined electrical and thermal stresses generated under dark and light conditions on the electrical efficiency and functional parameters of silicon based photovoltaic modules. To simulate the effect of the stress that can occur under standard working conditions, various reverse currents were injected under various temperature levels and irradiation powers in standard low-power commercial modules based on these experimental characterizations, changes in the efficiency and parameters of the cells and modules exposed to shadow effects are compared to that in normal working mode. Based on punctual I-V measurements, the characterization of the changes of the series and parallel resistances of PV modules produces good indicators of the aging, the health and local degradations as hot spots and allows to evaluate the effect of electrical stress under a given temperature on the performance of PV solar modules. Indeed, whatever is the temperature, the electrical stress created by a reverse current under light induced greater changes in both series and parallel resistances than applied in dark. This work points the huge degradation of performances of photovoltaic modules in abnormal working mode.
\end{abstract}

Keywords Solar Cell/Module, Photovoltaic, Electro-Thermal Stress, Shunt and Series Resistances, Dark and Light Conditions.

\section{INTRODUCTION}

In normal operation mode, solar photovoltaic (PV) modules convert the light energy coming from solar irradiation into electrical energy with efficiency directly dependent of the nature of the constituting material of the cells and the topology of the modules. Nevertheless, the maximum efficiency expected in normal operation mode is rarely achieved as, in real mode; various external parameters modified the behaviour of the PV modules. The real mode generally corresponds to a degraded working mode due to temperature and shading variations (e.g., snow, sand, tree, or bird dung covering the surface of PV modules) or non-uniform illumination inducing stresses due to mismatches, aging and local deterioration of the modules. This problem is more serious as the stressed cell must be considered as an element of a module composed by a combination of series and parallel strings of cells. In this case, the stressed cell can switch to a reverse operating mode leading to a huge power dissipation and thus to a thermal increase up to the creation of burning effects localised in the considered cell. In worst cases, this overheating can induce irreversible hot spots generating reverse current in the whole structure [1]. The solar cells that exhibited this hotspot effect operate as charge in the photovoltaic module, which significantly reduces the conversion efficiency of the entire PV panel creating local maximum power point, largely different of the expected global one. Within these functional conditions, the combined effects due to the creation of a reverse current inducing an increase of the temperature are known as the electro-thermal stresses of PV modules.

The purpose of this article is to understand the hot spot phenomenon by experimentally studying the electrical parameters characteristics before and after a combined electro-thermal stresses, i.e. the influence of temperature on the operation of PV modules due to a reverse current caused by hot spots. Various experiments were performed on 
solar modules and the experimental results have been analysis using well-know models describing the electrical functioning of a PV cell or module. We remember that these models are grouped into two families, the one-diode models and the two-diode models families. Clearly, the two-diode model is the most complete and the allow a highly precise analysis of the effects of electrical stresses and temperature variations on the characteristics and parameters of the photovoltaic modules. Therefore, the two-diode model is used to analyze the results presented in this paper.

The two-diode model associated to seven parameters is composed of two ideal diodes, a series resistance $\mathrm{R}_{\mathrm{s}}$ and a parallel shunt resistance $\mathrm{R}_{\mathrm{sh}}$, the other parameters being the voltages, the currents and the temperature [2].

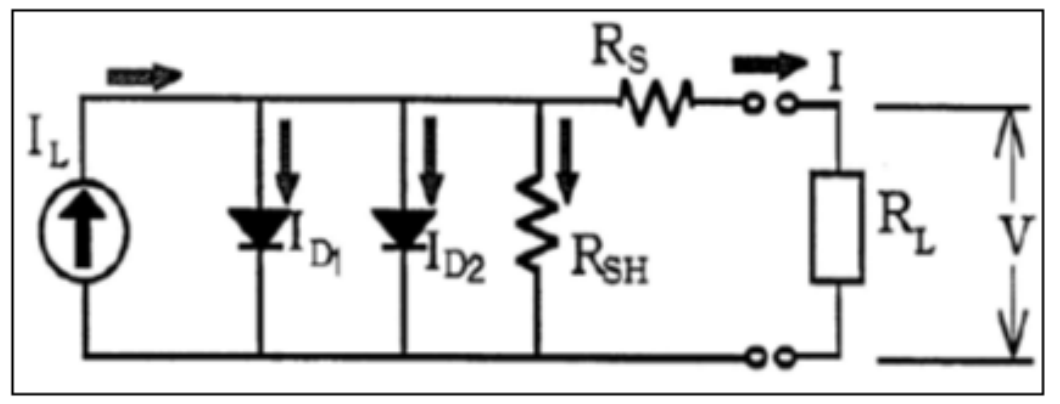

FIGURE 1. Idealized equivalent circuit of a double exponential model [3]

To calculate the parameters, the experimentally I-V curves were introduced into specially designed software as Matlab/Simulink that performs numerical calculations based on the double exponential model of a PN junction formulated by the following equation: [3]

$$
\mathrm{I}=I_{L}-I_{01}\left\{\exp \left(\frac{\mathrm{V}-\mathrm{R}_{\mathrm{S}} \mathrm{I}}{\mathrm{V}_{\mathrm{T}}}\right)-1\right\}+\mathrm{I}_{02}\left\{\exp \left(\frac{\mathrm{V}-\mathrm{R}_{\mathrm{S}} \mathrm{I}}{\mathrm{AV} \mathrm{V}_{\mathrm{T}}}\right)-1\right\}+\frac{\mathrm{V}-\mathrm{R}_{\mathrm{S}} \mathrm{I}}{\mathrm{R}_{\mathrm{Sh}}}
$$

where: I represents the intensity of the total cell (A); $\mathrm{I}_{\mathrm{L}}$ represents the photocurrent ; $\mathrm{I}_{02}$ is the reverse saturation current corresponding to generation and recombination of electrons and holes in the depletion region; $\mathrm{I}_{01}$ is the reverse saturation current corresponding to the diffusion and recombination of electrons and holes in the $\mathrm{P}$ and $\mathrm{N}$ side, respectively; $\mathrm{V}$ is the output voltage, $\mathrm{V}_{\mathrm{T}}=\mathrm{KT} / \mathrm{q}$ is the thermal voltage, $\mathrm{q}$ is the elementary electron charge $=1.6$ $\times 10^{-19} \mathrm{C}, \mathrm{k}$ is the Boltzmann constant $=1.38 \times 10^{-23} \mathrm{~J} / \mathrm{K}, \mathrm{T}$ is the absolute cell temperature, A is the ideality factor $>1$ and $R_{s h}$ is the shunt resistance, $R_{s}$ is the series resistance. [4]

Previous publications of our group explain the hotspot under other external and stress conditions [5-10]; they focused on the following points:

- $\quad \mathrm{I}-\mathrm{V}, \mathrm{C}-\mathrm{V}$ characteristics and parameters of PV solar modules under the influence of electrical stress.

- I-V, C-V characteristics and parameters of PV solar modules under the influence of thermal stress.

- I-V, C-V characteristics of PV solar modules under the influence of electro thermal stress.

In the ideal case, i.e. under theoretical and normal operating conditions and at ambient temperature, the series resistance equals zero $\left(R_{s}=0\right)$ and the shunt parallel resistance should be infinite $\left(R_{s h}=\infty\right)$. But, to analyze the influence of cell shading on the performance of the module, it is also important to determine and discuss the values of the shunt and series resistances that can be measured by classical I-V measurements. Thus, the series resistance, Rs mainly depends on the volume resistance of the semiconductor, the metal contacts and interconnections, the carrier transport through the diffusing layer, the contact resistances with the metal parts of the electrodes. It has small effect on the short-circuit current and can be determined from the I-V characteristics by the evaluation of derivative near the open circuit voltage, $\mathrm{V}_{\mathrm{oc}}$. 


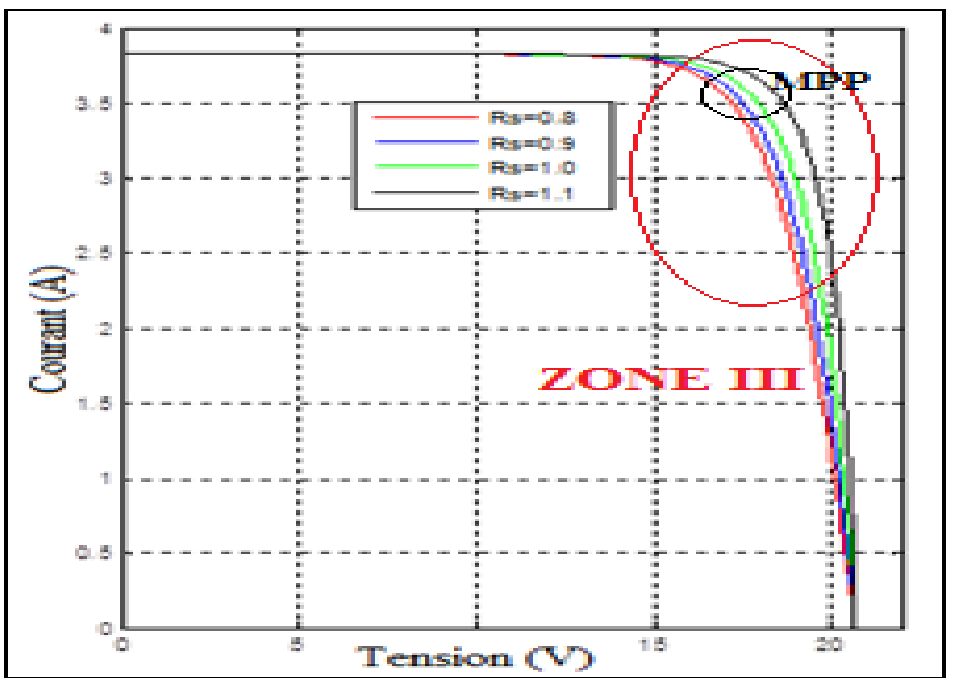

FIGURE 2. Influence of the series resistor $\mathrm{R}_{\mathrm{s}}$ on I-V characteristics from Ref. [11]

This variation increase the value of the optimal point on I-V curves corresponding to the maximum power point (MPP) with a small positive offset in the zone III where the module then functions as a voltage source. [12, 13]

The parallel resistance, Rsh is due to the impurities near the junction and to the fact that the PN junction in a crystalline module is not ideal inducing a leakage current. It can be determined from the curve I-V by calculating the derivative near Isc.

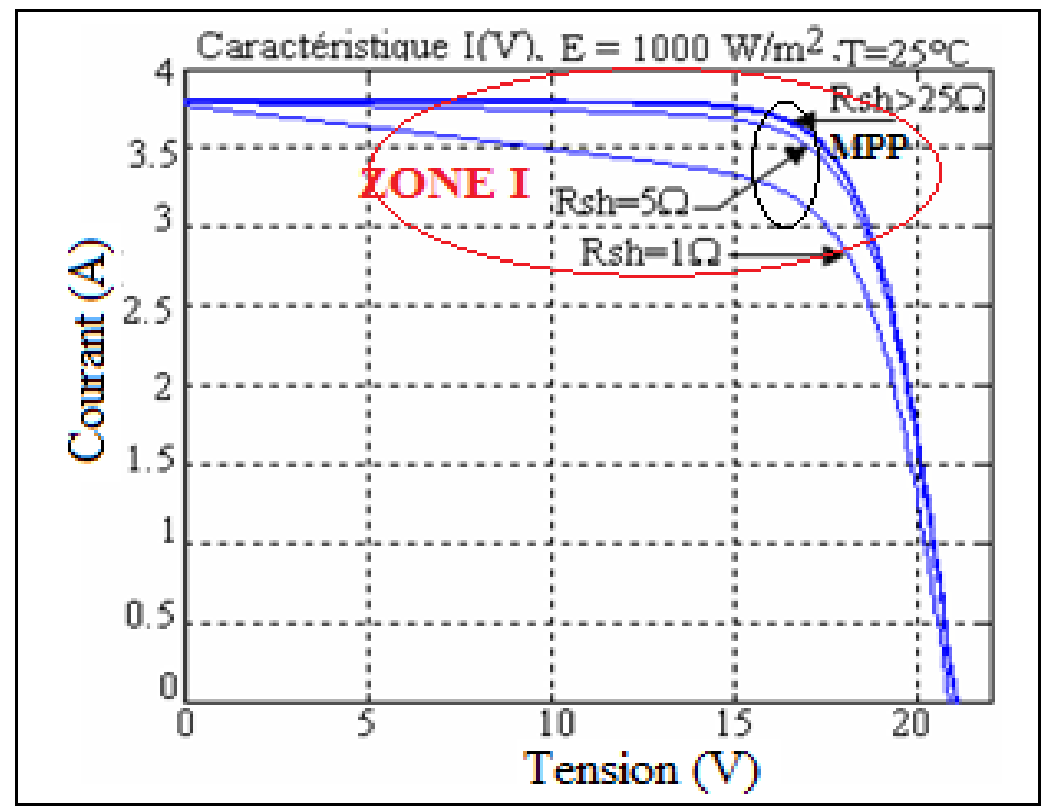

FIGURE 3. Influence of the shunt resistor $R_{\mathrm{sh}}$ on I-V characteristics from Ref. [14]

The variation of the shunt resistance increases the optimal point on I-V characteristic with a small positive offset in zone I where the module works as a voltage source.

Therefore, the resistors act on the slope of the I-V characteristic then the values of the current and the maximum voltage vary and affect the global efficiency of solar cell. In addition, their values are related to the structure and technology of the cell and we notice here the importance of using cells with high quality materials, especially materials that can stand high temperature and illumination as used in this study. 
Even if this contribution focuses on the electrical parameters of PV modules with stresses, it is to be noted that a leakage current in a cell will also induce a defect at the surface of the solar cell. We showed in Fig. 4 by scanning electron microscopy (SEM) that the surface of a stressed PV module can be burned inducing a degradation and a separation of the silicon and protective oxide layers of the module. [6]

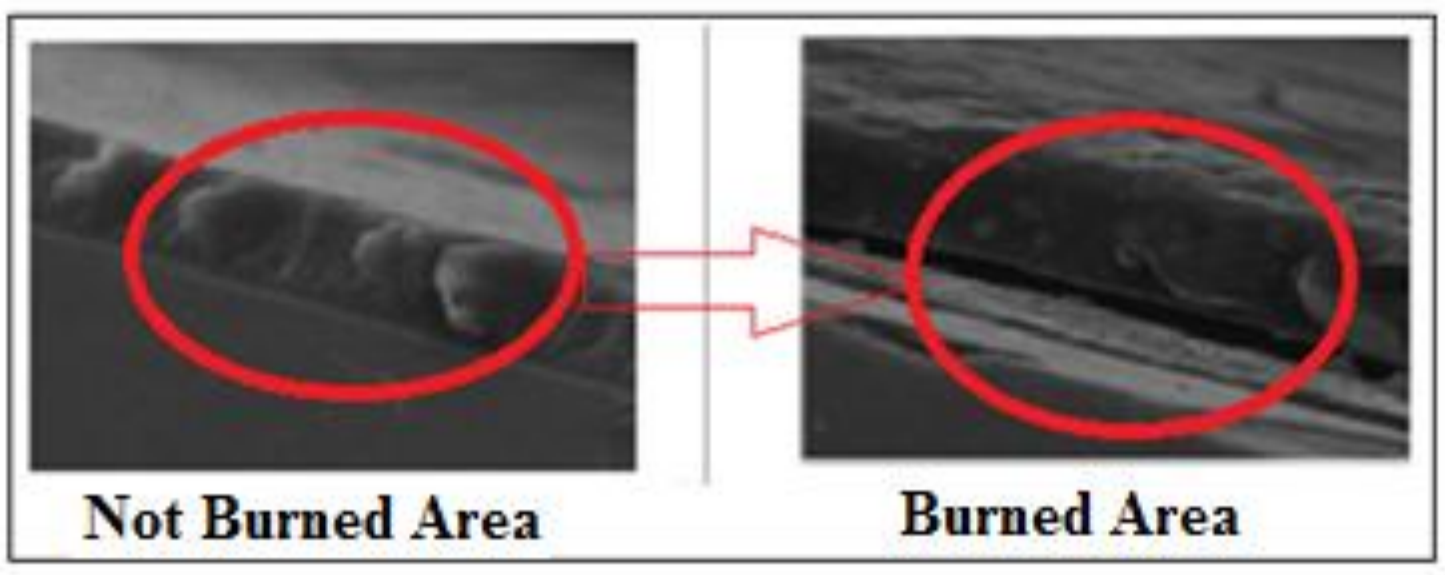

FIGURE 4. Scanning electron microscope (SEM) not burned and burned area [6]

Thus, the aims of this paper are the study of the effect of the hotspot phenomena on the performance of photovoltaic modules, in real cases. For that purpose, as describe below, in the stressed phase, we applied an electrical reverse current at various temperature in dark and under light conditions. In the characterization and modeling phase, we compare the behaviors of $R_{s h}$ and $R_{s}$ as measured when the modules are illuminated or not (Measurements in dark of with light). The results and discussion brings some responses to the origin of the decrease in the efficiency of panels and modules in real conditions, it aims to contribute in the material and PV system performance analysis.

\section{EXPERIMENTAL METHODOLOGY}

For studying the effect of the combined electro-thermal stresses, we present a series of experimental measurements using a series of $3.8 \mathrm{~V}$ and $0.3 \mathrm{~W}$ commercial photovoltaic modules with dimensions $60 \times 60 \mathrm{~mm}$. During this study, the reverse current varied from $10 \mathrm{~mA}$ to $40 \mathrm{~mA}$ in steps of $10 \mathrm{~mA}$, injected into the photovoltaic modules at various temperature varying from $25^{\circ} \mathrm{C}$ to $100^{\circ} \mathrm{C}$, by steps equal to $25^{\circ} \mathrm{C}$, in dark and under light at 10klux. The electrical parameters were measured under the same conditions by fixing the time interval to 10 minutes for each dose of stress. This time interval was checked to be sufficient to achieve a saturation level corresponding to the induced stress effect in the whole considered stress range.

This experimental study consists of two main parts corresponding to the creation of combined electro-thermal stresses (SET). In the stress phase SET1, the stress is induced in a cell placed in dark condition and in the stress phase SET2 the same stress is induced in the cell placed under light condition. After the both SET phases, the electrical parameters were measured in dark (SET1-1, SET2-1) and under light (SET1-2, SET2-2). The experimental procedure is summarized in figure 5 . 


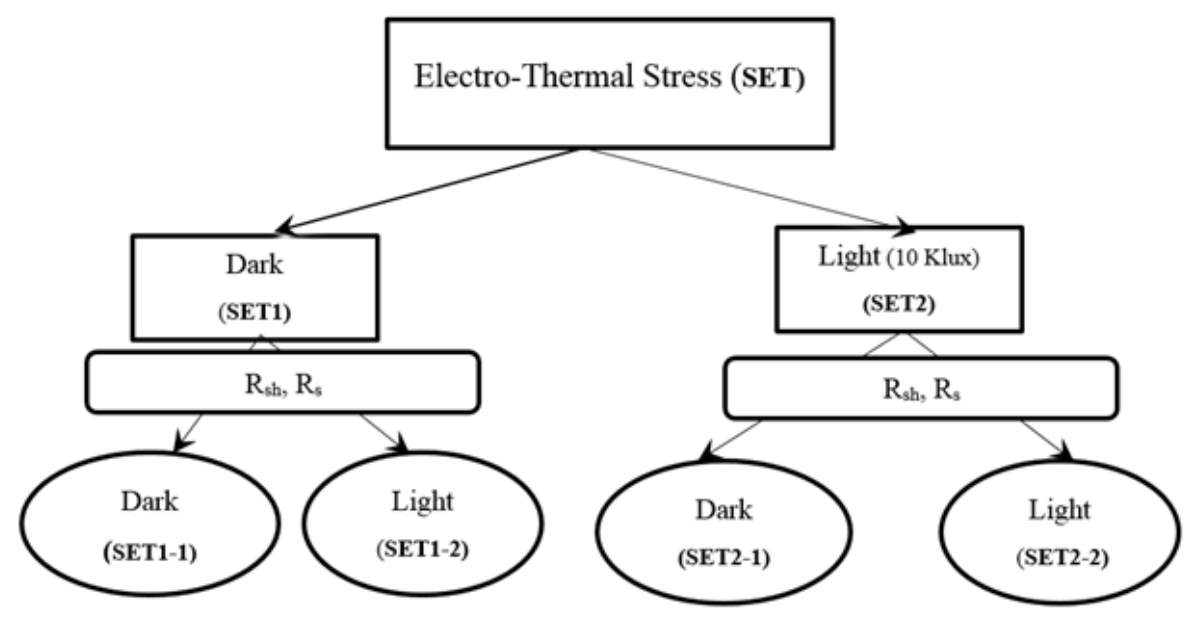

FIGURE 5. Experimental Procedure

In all the following figures, the reference values of the parameters of the cell are considered for the virgin module i.e. without reverse induced current and at ambient temperature.

\section{RESULTS AND DISCUSSIONS}

The values of the resistances $R_{s h}$ and $R_{s}$ are deduced from the experimental $I-V$ characteristics then extracted from the equation of the the two-diodes model through the dedicated Matlab program developed during this work. The shunt resistance corresponds to the inverse of the slope of the linear part of the I-V characteristic in the reverse bias case, and can be calculated as follow:

$$
\mathrm{R}_{\mathrm{sh}}=\frac{V}{I_{S C}-I}
$$

Where: $I_{\mathrm{sc}}$ is the short circuit current, $\mathrm{V}$ and $\mathrm{I}$ is the voltage and current obtained experimentally.

In a previous publication by Zaraket et al. [10], we have given all necessary details about the parameters of the studied PV modules, which are the same that those studied in the current contribution. In Ref. [10], we have also presented the I-V characteristics under stress and focalized the previous analyzed on the consequences of the stresses on the hotspot heating.

In Figs 6 and 7, we plot the changes in the shunt and series resistances, respectively, with the temperature for different values of combined electro-thermal stresses under dark and light conditions (corresponding to the notations SET1 and SET2 in Fig. 5) based on the I-V characteristics determined in dark (SET1-1 and SET2-1) and under light (SET1-2 and SET2-2) and as detailed in Ref. [10]. In Figs. 6 and 7, the values of $R_{\text {sh }}$ and $R_{s}$ without stress are also represented by a point at room temperature. It is to be noted that the temperature considered in Figs. 6 and 7 correspond to the temperature of the module during the experimental stress step, and that the measurements were done at room temperature. 


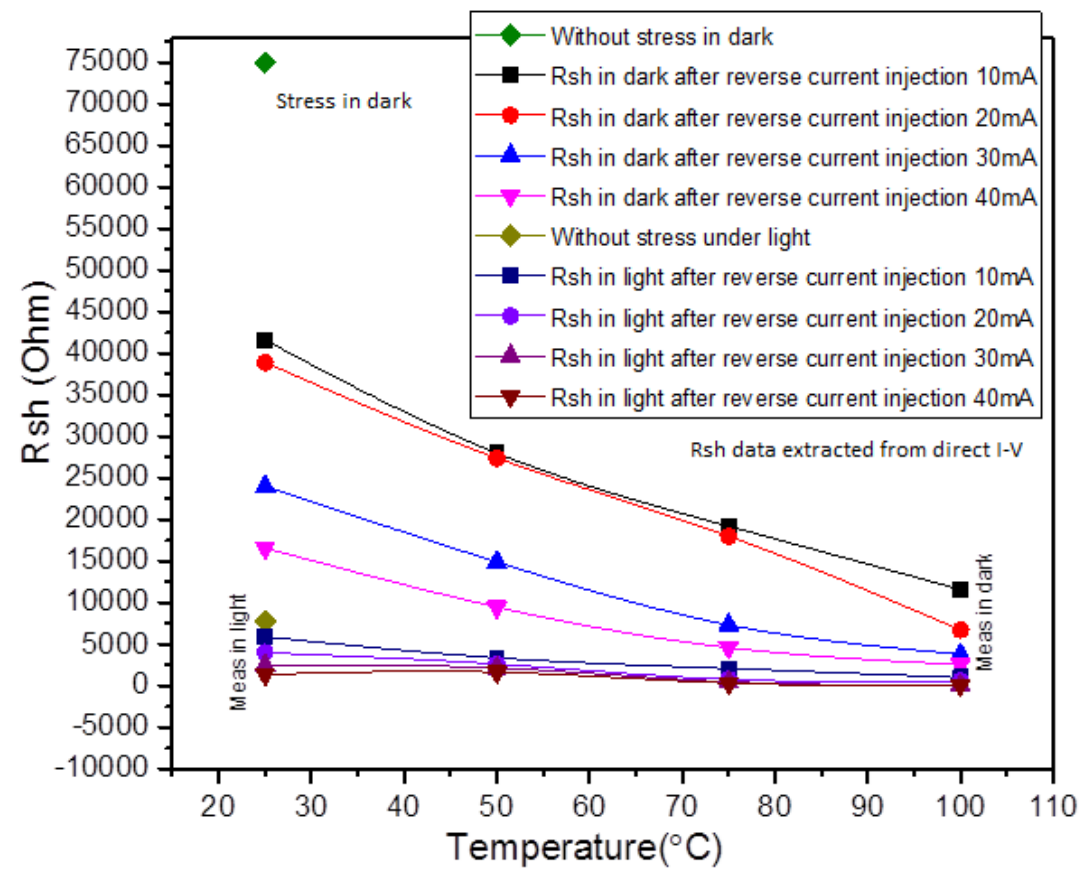

FIGURE 6.a. $\mathrm{R}_{\mathrm{sh}}=\mathrm{fct}(\mathrm{T})$ SET1 corresponding to the electro-thermal stress induced in dark condition, measurements in dark and under light.

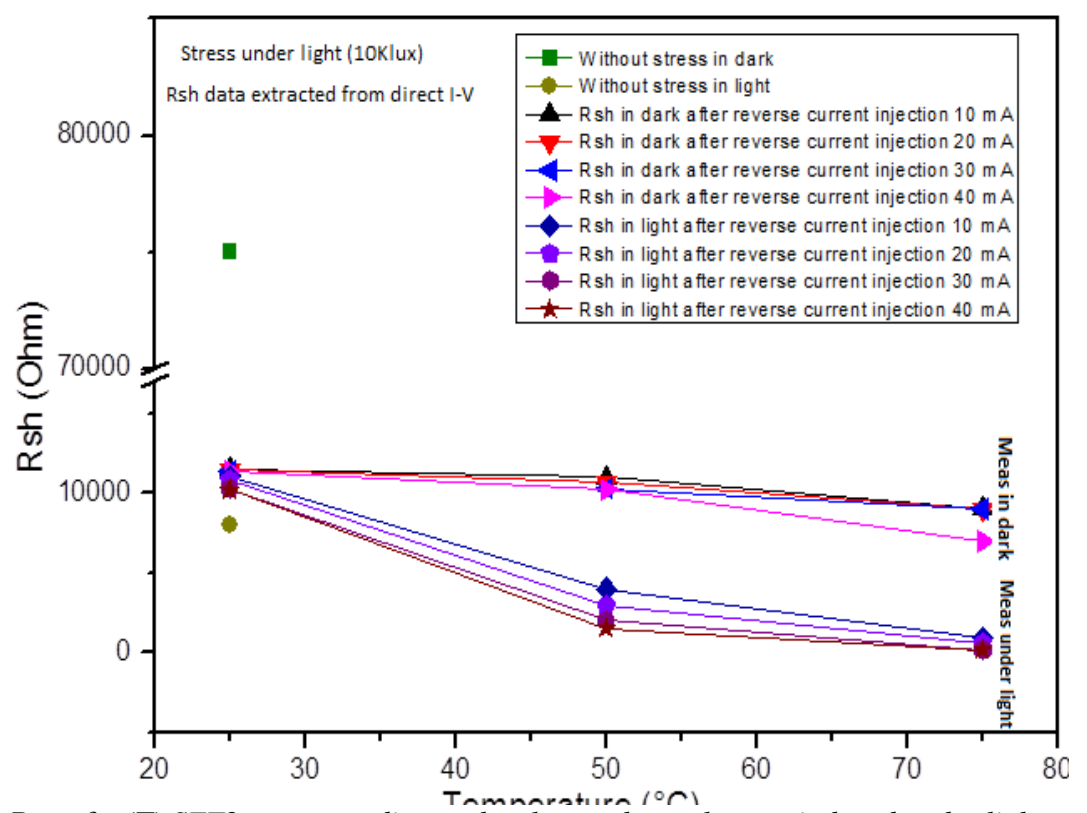

FIGURE 6.b. $\mathrm{R}_{\mathrm{sh}}=\mathrm{fct}(\mathrm{T})$ SET2 corresponding to the electro-thermal stress induced under light condition,

measurements in dark and under light.

At first, we analyzed the general shape of the $\mathrm{R}_{\mathrm{sh}}$ behavior as observed in both Figs. 6. We notice in both Figs. 6 an initial huge decrease of $\mathrm{R}_{\mathrm{sh}}$ immediately when an electric stress (SET1 and SET2) is applied as notice by the difference between the upper point (green point) and the origin of the various characteristics. We also notice that the shunt resistance decreases with the intensity of the reverse current and with the temperature whatever the external lighting conditions when the stresses are applied (Figs 6.a and 6.b) and also whatever the external lighting conditions during the measurements (in dark or under light). Nevertheless, whatever were the stress conditions for 
the light, $\mathrm{R}_{\mathrm{sh}}$ measured in dark (SET1-1 and SET2-1) is always greater than this measured under light (SET2-1 and SET2-2).

By else, always with a comparison of results presented in both Figs. 6, we notice that $\mathrm{R}_{\text {sh }}$ measured after a stress in dark conditions SET1 (Fig. 6.a) is always greater than this measured after a stress induced under light SET2 (Fig 6.b). The differences between Fig. 6.a and Fig. 6.b enlighten the straightforward contribution of the photocurrent in the internal conduction and damage process that occur in a semi-conductor photovoltaic junction. This decrease, closely linked to the I-V characteristics behavior [10] can be considered as the signature of an increase, for a part of the leakage current at the surface of PV module. This interpretation is fully justified by the creation with the inverse current of defects at the surface of the cell, as observed in the SEM photos of Fig.4, due to an increase of the temperature with the intensity of the reverse current. By else, the origin of the decrease of the shunt resistance can be found in the creation and evolution of deep defects into the junction, straightforwardly linked to the increase of the leakage current as function of the stress.

Now, with the same light conditions in the stress phase, as example, in Fig. 6.a, in the temperature studied range, after an electrical stress induced from $25^{\circ} \mathrm{C}$ to $100^{\circ} \mathrm{C}$ in dark conditions, the measurements of the relative variations of $\mathrm{R}_{\mathrm{sh}}$ of the module is $72 \%$ when measurements are done in dark and $83 \%$ when they are done under light. This difference points that the defects created by the stress are more active under light than in dark conditions during the measurement phase. In both experimental conditions, in dark or under light, we can see that a change of $75^{\circ}$ induce a variation of $R_{s h}$ of about the same amplitude that the variation that will be induce by a change in the reverse current of $30 \mathrm{~mA}$.

Within the same approach, the series resistance was measured from the reverse of the slope at the high voltages of the I-V characteristics, and can be calculated as follow:

$$
R_{S}=\frac{V_{o c}-V}{I}
$$

We remember that $\mathrm{V}_{\mathrm{oc}}$ is the open circuit voltage, $\mathrm{V}$ and $\mathrm{I}$ is the voltage and current experimentally obtained.

Following the same description procedure as for $\mathrm{R}_{\mathrm{sh}}$, in Figs. 6, with start the analysis of the influence of the stress on $\mathrm{R}_{\mathrm{s}}$ by the description of the common behavior observed in both Figs 7, before and after electro-thermal stress induced in dark (SET1) and under light (SET2) conditions. When an electric stress is applied, Rs immediately decreases as shown by the difference of the upper point (green point) and the origin of all characteristics. After this initial decrease, Rs continues to decrease with the intensity of the thermal stress in both lighting measurement conditions. In the same way, $\mathrm{R}_{\mathrm{s}}$ always decreases with the intensity of the reverse current whatever the temperature and whatever the light conditions during the stress phase. Moreover, $\mathrm{R}_{\mathrm{s}}$ measured in dark conditions (SET1-1 and SET1-2) is always higher than this measured under light condition in both cases (SET2-1 and SET2-2) (Figs 7.a and 7.b).

The variation of $\mathrm{R}_{\mathrm{s}}$ after stress in dark SET1 (Figs 7.a) is greater than this induces under light condition SET2 (Figs 7.b) pointing, here also, the influence of the photocurrent in the conduction properties of the photovoltaic junction.

By else, for measurements under dark condition, when the temperature varied from $25^{\circ} \mathrm{C}$ to $100^{\circ} \mathrm{C}$, the measurement of the relative variations of $R_{s}$ is $15 \%$ whatever are the initial electrical stresses conditions $(10,20,30,40 \mathrm{~mA})$. This relative variation of $\mathrm{R}_{\mathrm{s}}$ shows that the temperature amplifies the effect of the electrical stress, that can be explained by a greater increase in the number of deep defects in the junction at high temperature than at ambiant.

Finally, it is important to remember that in real situation, punctual damage in a photovoltaic module is created by an internal defect appearing due to aging or mismatches in the photovoltaic properties along the whole surface or created by a local dark zone due to external phenomena as shadows or stains at the origin of the increase of the electric and thermal stresses when the panel or module is globally under solar illumination. Thus, in our experiments, the stresses measured under light are the most closer to the real situation. 


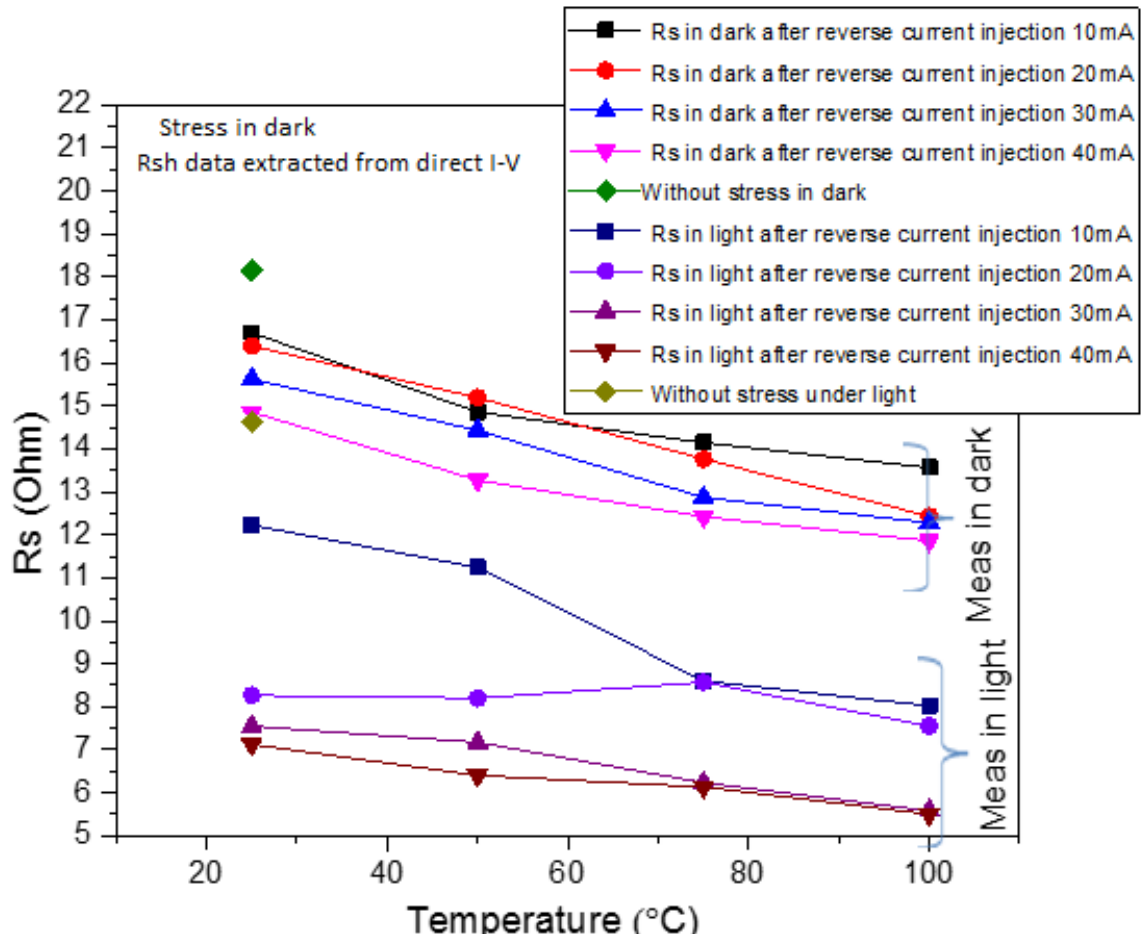

FIGURE 7.a. $\mathrm{R}_{\mathrm{s}}=\mathrm{fct}(\mathrm{T})$ SET1 corresponding to the electro-thermal stress induced in dark condition, measurements in dark and under light.

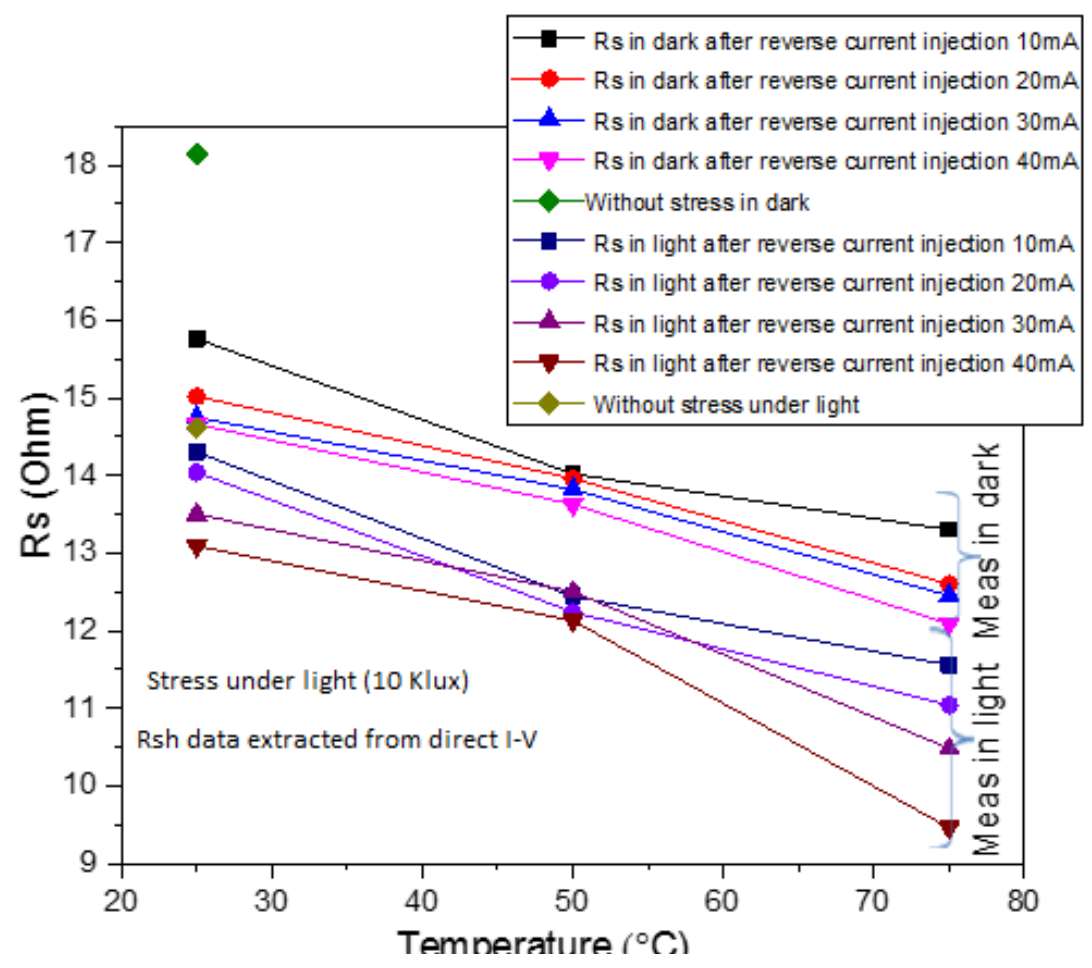

FIGURE 7.b. $\mathrm{R}_{\mathrm{s}}=$ fct $(\mathrm{T})$ SET2 corresponding to the electro-thermal stress induced light condition, measurements in dark and under light. 
Thus, we have shown that the determination of the decreases of the resistances of a module can be a good indicator of the level of stress he endured. By else, we have shown the large influence of the stress on the efficiency of a module, and that its consideration has to be taken into account in the design of such energetic systems. It is to be noted that this consideration is generally considered by manufacturers of PV modules with the integration of bypass diodes [15] adding safety precautions against the occurrence of hot spots resulting from the influence of temperature and reverse currents $[16,17]$.

\section{CONCLUSION}

The electrical parameters of PV solar modules were studied considering the behavior of the series and parallel resistances before and after an electrical stress induced at various temperatures in dark (SET1) and under light (SET2) conditions and finally also determined after measurements in dark (SET1-1 and SET2-1) and under light (SET1-2 and SET2-2) .

In this contribution, we have shown the huge influence of the thermal, electrical and electro-thermal stresses (SET) in the change of the resistances of the module.

Whatever is the temperature, the electrical stress created by a reverse current under light induced greater changes in both series and parallel resistances than applied in dark. This effect is interpreted by the role of the photocurrent in the conduction process in a photovoltaic junction these results were clearly seen by comparing the shunt and series resistances in dark and under light conditions. Indeed, the photocurrent decreases the shunt resistance i.e. the leakage current increases and produces some burnt and destroyed zones in the module.

Practically, it is important to analyse the effect of reverse current under temperature for both cases and applied this experimental methodology for solar cells, arrays, and even a farm of arrays creating a photovoltaic solar generator. We have shown that based on punctual I-V measurements during the life of a module, the characterization of the changes of the series and parallel resistances produces good indicators of the aging, the health and local degradations as hot spots and allows to evaluate the effect of electrical stress under a given temperature on the performance of PV solar modules.

\section{REFERENCES}

1. R. Ramabadran, B. Mathur, "Effect of shading on series and parallel connected solar PV modules", Modern Applied Science, 3(10), 32- 42 (2009).

2. H. Tsai, C. Tu, Y. Su, "Development of generalized photovoltaic model using MATLAB/SIMULINK", Proceedings of the World Congress on Engineering and Computer Science 2008, WCECS 2008, October 22 24, San Francisco, USA, 2008.

3. C. Salame, R. Habchi, "Silicon MOSFET devices electrical parameters evolution at high temperatures", Microelectronics International, 25(1), 21-24 (2008).

4. D. Lugo-Munoz, J. Muci, A. Ortiz-Conde, F. J. Garcia-sanchez, M. de Souza, M. A. Pavanello, “An explicit multi-exponential model for semiconductor junctions with series and shunt resistances", Journal Microelectronics Reliability, 51, 2044-2048, (2011).

5. J. Zaraket, M. Aillerie, C.Salame, "Capacitance Evolution of Photovoltaic Solar Modules under the Influence of Electrical Stress", Energy Procedia, Elsevier, 74, 1466-1475 (2015).

6. J. Zaraket, M.Aillerie, C. Salame, "Dark and Illuminated Characteristics of Photovoltaic Solar Modules. Part I: Influence of Dark Electrical Stress", AIP-CF 1758, 020016 (2016).

7. J.Zaraket, M. Aillerie, C. Salame, "Dark and Illuminated Characteristics of Photovoltaic Solar Modules. Part II: Influence of Light Electrical Stress", AIP-CF, 1758, 030052 (2016).

8. J. Zaraket, T. Salame, M. Aillerie, C. Salame, "Parameters and Characteristics of PV Solar Modules under the Influence of Thermal Stresses", AIP-CF, 1814, 020055 (2017).

9. J. Zaraket, M. Aillerie, C. Salame, "Capacitance evolution of PV solar modules under thermal stress", Energy Procedia, Elsevier, 119, 702-708, (2017).

10. J. Zaraket, T. Khalil, M. Aillerie, G. A.Vokas, C. Salame, "the Effect of Electrical stress under temperature in the characteristics of PV Solar Modules", Energy Procedia, Elsevier, 119, 579-601 (2017).

11. Published by bloggerinfo 27, in «Green enivrement », end of study memory on PV cells, chap ii-iii, p 26-30, 2013. 
12. O.M. Yahya ; Etude et modélisation d'un générateur photovoltaïque ; Revue des Energies Renouvelables, 11(3) (2008).

13. Z.M. Salaeh, Optimum Switching Points for Array Reconfiguration Controler; Department of electrical Engi University of lowell MA 01854. IEEE, 971-976. 1990.

14. B.Mohammad ; " Modélisation des phénomènes de vieillissement des modules Photovoltaïques", Mémoire de Magistère, Université Abou-Bakr Belkaïd-Tlemcen, Algéria, 2012.

15. W. Herrman, W. Wiesner, W. Vaaßen, "Hot spot investigation on PV modules- new concepts for a test standard and consequences or module design with respect to bypass diodes", Photovoltaic Specialists Conference, 1997, Conference Record of the Twenty-Sixth IEEE, CA, USA, 1129-1132, 1997.

16. W. Herrman, M. Adrian, W. Wiesner, "Operational behavior of commercial solar cells under reverse biased conditions", 2nd WCPEC, Vienna, 2357-2359, 1998.

17. H. Oldenkamp, "Detailed analysis of currents in PV-shunts", Technical note which set the basics for PVwirefree, OKE-services, 1-6, 2002. 